\title{
Children's Facebook Usage: Parental Awareness, Attitudes and Behavior
}

\author{
Asnat Dor ${ }^{1} \&$ Dana Weimann-Saks ${ }^{2}$ \\ ${ }^{1}$ Department of education, Emek Yezreel Academic College, Israel \\ ${ }^{2}$ Department of Behavioral Science and Social Science, Kinneret Academic College, Israel \\ Correspondence: Asnat Dor, Department of education, Emek Yezreel Academic College, Emek Yezreel 19300, \\ Israel. Tel: 972-4-642-3561. E-mail: dorasnat@ gmail.com
}

\author{
Received: October 29, 2012 Accepted: November 13, 2012 Available online: December 17, 2012 \\ doi:10.11114/smc.v1i1.28 URL: http://dx.doi.org/10.11114/smc.v1i1.28
}

\begin{abstract}
The study aims to focus on parental awareness, attitudes and behavior regarding children's use of the world's largest social network - Facebook. Data were obtained from 195 Israeli parents, Jews and Arabs whose children are above and under the age of 13 (official age to start registration to Facebook). Analyses included variance analyses, correlations, and regressions.

The results indicated that parents have moderate to low levels of awareness, involvement, and monitoring in their children's Facebook usage. However significant differences were found between mothers and fathers, as mothers expressed less positive attitudes toward Facebook and greater need for guidance than fathers. Arab parents expressed higher levels of monitoring and of need for guidance than Jews.

Our findings highlight the need for usage regulation and for guidance for parents in order to help them direct their children toward safe and responsible use of the internet.
\end{abstract}

Keywords: monitoring children's Facebook usage, attitudes toward Facebook, familiarity with Facebook, need for guidance, co-using Facebook

\section{Introduction}

The first decade of the twenty-first century saw the rapid spread of internet use, and internet use keeps growing by the day. The internet has become an integral component of life for most people in the industrialized countries, serving all ages for learning, communication, information gathering and entertainment (Bjornstad \& Ellingsen, 2004; Liau, Khoo, \& Ang, 2005; Livingstone, 2003; Livingstone \& Bober, 2004; Steyer \& Clinton, 2003; Wartella, Lee, \& Caplovitz, 2002). Since the launching of Facebook in 2004, internet use has increased, especially among children and adolescents (Johansson \& Gotestam, 2004), and researchers are now turning their attention to the large number of children who have free access to the internet, and to the long hours they on it (Cho \& Cheon, 2005; Livingstone \& Bober, 2005). According to Lenhart and Madden (2007) about 93\% of the teenagers in the USA use the internet, more than three-quarters $(76 \%)$ have internet access at home, and about $63 \%$ go online every day. About $73 \%$ of American teens use social networking websites and this rate is has grown consistently over the last years (Lenhart, Purcell, Smith, \& Zickuhr, 2010).

Does internet use have long-term effects on the development of children and adolescents? On the one hand, the internet affords many opportunities for learning, entertainment; enrichment, and personal growth. Therefore parents have a positive view of its use, and encourage children and adolescent to do so. On the other hand, parents are ambivalent to the internet, as they are aware of the potential risks it carries by exposing uses to negative content such as pornography, violence, commercialism, cyber bullying, unsupervised social relations and privacy and security issues (Ceyhan, 2011). Parents are concerned about their children's social, cognitive, and psychological development, and worry about possible effects such as increased aggression, antisocial behavior, addiction problems, poor school performance, low self-esteem, and identity confusion (Cho \& Cheon, 2005; Fleming \& Rickwood, 2001; Lăzărescu, 2010; Wartella et al., 2002). Although such negative effects may impact the adult population as well, younger people may be more susceptible (Finkelhor, Mitchell, \& Wolak, 2000; Kim, 2007; Lenhart, 2005; Lim, Khoo, \& Williams, 2003). 


\subsection{Children, Adolescents, Adults - and the Internet}

According to Prensky (2001) those who were born after 1986, can be called digital natives, as they were born into a world in which the internet is ubiquitous. The digital natives are different from their parents' generation, the digital immigrants, who had to learn this technology as adults. According to the research teenagers are those who are most likely to guide and explain computer usage to other members in the family (Cole, Suman, Schram, Van Bel, Lun \& et al., 2000; Kiesler, Zdaniuk, Lundmark, \& Kraut, 2000; Mesch, 2003). Nevertheless, the generational difference lead to a digital gap, not only is facility of use but in attitude. In general, children seem to be much less concerned and anxious than their parents about possible future risks relating to the internet (Livingstone, 2003). For instance, children tend to feel more comfortable to contact strangers online, while parents are more concerned about the risks that might accompany it (Lim et al., 2003). The children easiness is especially worrying in light of the report by the American National School Boards Foundation (2008), according to which children lack key skills to evaluate properly online content and internet risks. According to Livingstone and Bober (2005) 18\% of UK parents feel they lack the ability to help their child use the internet safely, and about $80 \%$ of them wish for stricter regulation of online services, and better information and advice for parents.

\subsection{Parental Monitoring of Children Internet Usage}

Despite parents' concern over the potential dangers of the internet on young users, Cho and Cheon (2005) claim that about $30 \%$ of the parents do not discuss these dangers with their children. According to Liau et al. (2008) most parents do not exercise significant supervision over their children's activity on the web. Parents seem to be aware of such activity when the children first engage in it, and supervision wanes over time. However, most parents whose child has access to the internet claim that they share and/or support their child on the internet, a claim not embraced by their children (Liau et al., 2008; Livingstone \& Bober, 2005). Specifically, parents instruct their kids on safe conduct on the internet (e.g., "Don't give personal information to strangers"), and they assume that their children follow their instructions. However, surveys show that this is rarely the case, and children often divulge personal information (Lenhart \& Madden, 2007; Livingston \& Bober, 2004).

In their research, Livingston and Bober (2004) point to a discrepancy between the large numbers of children who admit to being exposed to pornography, and a significantly smaller number of parents who are aware of their children's exposure to it. Children also report longer hours of daily use than their parents report, and admit, more often than their parents are aware of, that they are exposed to some kind of online harassment (Cho \& Cheon, 2005; Liau et al. 2008; Livingston \& Bober, 2004). According to Boniel-Nissim (2010), the digital gap between parents and children, may also explain why adults avoid enforcing rules and norms for safe internet conduct. Parents lack the necessary skills and knowledge, resulting in what can be interpreted as permissive behavior.

While many parents are not aware of the full extent of their children's online activity, mothers were found to be more aware of their adolescents' internet use than fathers (Liau, Khoo, \& Ang, 2008). This finding may be explained by the fact that mothers, more than fathers, spend more time with their children in conversation, joint activities, and caregiving (Garcia-Mainar, Molina, \& Montuenga, 2011; Waizenhofer, Buchanan, \& Jackson-Newsom, 2004). However, as regard to internet use, other research (Bjornstad \& Ellingsen, 2004; Wang, Bianchi, \& Raley, 2005) indicates that fathers tend to be more involved than mothers and are more likely to check the websites their children had visited. Although parents acknowledge the importance of supervising children's internet activity, the research literature reveals an inconsistent picture of parental monitoring and supervision (Liau et al., 2008).

To date, no correlation has been found between active parental monitoring (sitting with a child, or visiting the sites the child has been to) and adolescents' Internet risky behavior (Liau et al., 2005; Mitchell, Finkelhor, \& Wolak, 2001). However, some studies have shown that risky internet behavior is less likely to occur among adolescents who tell their parents that they have received inappropriate content (Liau et al., 2008; Sook-Jung \& Young-Gil, 2007). Lee and Chea (2007) also found that "parental mediation of the Internet has positive outcomes when parents are actively involved in their children's Internet use through processes such as recommending web sites and co-using. Simply prohibiting or restricting seems ineffective for guiding children's Internet use" (p. 644). Sun, Unger, Palmer, Gallaher, Chou et al., (2005) found that less parental monitoring was related to more internet use by children, leading to the conclusion that "more research needs to be done to gain a better understanding of parental awareness of adolescents' Internet use as well as the amount and types of parental monitoring with regards to Internet use" (Liau et al., 2008, p. 220).

The new possibilities and pitfalls open to children on the internet make new demands on parental responsibility for their children's safety and their ability to meet these demands. The aim of this study is to learn about parents' attitudes to their children's Facebook activity, and their monitoring behavior of this new venue for social 
networking.

\subsection{Facebook and Facebook Usage in Israel}

Facebook is a free social network that enables its users to share pictures and files with other users. Among the social networks, Facebook is the world's largest, with more than a billion users (News1, 2012). According to Inside Facebook.com (2010), the number of users declines with age - about $63 \%$ of Facebook users are 34 and under. Following reports of tragic outcomes and child abuse (Gray \& Christiansen, 2010; O'Keefe \& Clarke-Pearson, 2011), public criticism of Facebook-related dangers has emerged. At the same time, new research implies good social outcomes derived from Facebook usage, as a comfortable environment to strengthen social relations (Baker \& Oswald, 2010). In response to both views, Facebook is designed to protect young children, and its policy is that no one younger than 13 can register. However, many younger children falsify their date of birth and register, and often do so with their parents' knowledge (Boniel-Nissim, 2010).

Israel, where this study is conducted, is a multi-ethnic and multi-national state. Out of a population of approximately 7.5 million people (Israel Census Bureau, 2010), the largest ethnic group is Jewish, which as a whole, can be characterized as a modern society with a Western orientation. The second largest ethnic group about $25 \%$ - is Arab, mostly Muslim. This group is generally characterized as a traditional, conservative society (Sagy, Orr, Bar-on, \& Awwad, 2001; Sivan, 1995), patriarchal, authoritarian and collective which is exposed to and influenced by a modern, Western lifestyle (Dwairy \& Achoui, 2006). In Israel Facebook is also the most popular social network, with some 600,000 registered. Of these, about $80 \%$ are under 34 , and within this age group, about 20\% are 13-17 (http://www.kav-lahinuch.co.il/?CategoryID=428andArticleID=3234). Of the estimated 1.3 million Israelis age 10-19 (Israel Census Bureau 2010), about half use the internet on a daily basic (Vax, 2011). A comparison of Facebook use among Jewish and Arab Israeli children and adolescents reveals that almost $75 \%$ of Jewish children are registered to Facebook, compared to about $25 \%$ of the Arab children (Kan-Naim, 2011).

Aim of this study

The current study was designed to gain in-depth understanding of parents' awareness of, and attitudes and behavior toward their children's Facebook use. More specifically, the study focuses on five aspects (1)Parents' attitudes toward Facebook, (2) Monitoring children's usage, (3) Co-using Facebook with children, (4) Parents' familiarity with Facebook, and (5) Parents' feelings of need for guidance on how to monitor their children's usage.

The study compares Jews and Arabs in Israel, in addition to dividing between gender of parents and between parents of children in different age groups (under 13 and over 13).

\subsection{Research Hypotheses}

In accordance with the research literature surveyed above, several hypotheses are presented:

1. Mothers will show higher levels of monitoring, co-using, and need for guidance than fathers, as well as less positive attitudes and less familiarity with Facebook than fathers.

2. Jewish parents will express more positive attitudes toward children's Facebook use, higher levels of co-using, and greater familiarity than will Arab parents. Arab parents will express higher levels of monitoring children's Facebook use, and higher needs for guidance on how to monitor this use.

3. Parents of children under 13 will exhibit higher levels of monitoring, higher levels of co-using, and a greater need for guidance that parents of children age 13-19

\section{Method}

\subsection{Participants Characteristics}

Participants were 195 parents - $119(61 \%)$ mothers and 76 (39\%) fathers. Measures included demographic questions referring to the participants, such as the participants' gender, ethnicity, age, their children's age, socioeconomic status, and education. Most of the participants (85.2\%) are 31-50 years old, and 67\% of these had children under the age of 13 . The Children ranged in age from 8 to 17 years $(\mathrm{M}=11.88, \mathrm{SD}=2.01)$, while most of them (87.2\%) ranged from 8 to 15 . Ethnically, $65.1 \%$ of the participants were Jewish and $34.9 \%$ Arabs. Most of the participants $(91.3 \%)$ were married, from medium-socioeconomic background; $83.1 \%$ were native Israelis and $91.9 \%$ lived in north of Israel, in three medium-size towns of medium-low to medium socioeconomic status. About $65.5 \%$ were highly educated $(46.4 \%$ have a BA, $16.5 \%$ have an MA, and $2.1 \%$ have a PhD). All of the participants had a computer at home and about $67 \%$ had more than one computer. About $61 \%$ of the participants said the computer at home was either in the child's room or in another place where the user has privacy. Of all 
the participants, $81 \%$ say that their child has a Facebook account; almost $70 \%$ do not know their children's Facebook password. Of the participating parents, $46.2 \%$ had a Facebook account, and $12.8 \%$ of them say that they have it in order to supervise their children's activity on Facebook. The rest are registered for their own use.

A comparison between the characteristics of the Jews and the Arabs revealed few significant differences. More Jewish families than Arab ones had two or more computers at home $\left(\chi^{2}(3)=16.07, r_{c}=0.29, p<0.001\right)$, and more Jewish parents and Jewish children have active Facebook accounts than do Arab parents and children $\left(\chi^{2}(2)=5.50, \phi=0.22, \mathrm{p}<0.05\right) ; \chi^{2}(2)=7.92, \phi=0.21, p<0.05$ respectively). In all other variables (parents' level of education, parents' knowing the child's Facebook password, reasons why parents register and computer location at home), no significant differences were found.

\subsection{Research Design}

The questionnaire that was used, was developed especially for this research. First, MA students, from a department of education in a medium-sized academic institution in the north of Israel, suggested a pool of 64 items about parents' behavior and attitudes toward their children's use of Facebook. Examining the items revealed that they represented five aspects: Parents' attitudes toward Facebook, Monitoring children's usage, Co-using with children, Parent's level of familiarity with Facebook, and Parents' feelings of need for guidance on how to monitor their children's usage. As a second stage in the questionnaire development, this pool of items was given to 21 evaluators (MA students of educational counseling), who were asked to classify each one of the items into one of the five aspects. An items that was classified unanimously by all evaluators was included in the questionnaire, bring the final number of items to 39. Participants were asked to rate them on a four-point Likert scale (1 - Strongly disagree, 4 - strongly agree). In addition, the questionnaire included 18 demographic items (gender, age, level of education, etc.), and items regarding awareness and involvement in internet and Facebook usage in their home (number and location of computers at home, parents' usage of Facebook, parents' knowing the child's password).

A series of principal components factor analyses (PCA) with Varimax rotation was conducted to determine construct validity, referring to the five factors identified in the questionnaire development process. We considered an item to be part of a factor if it had high loading (greater than .45). 12 items appeared to represent monitoring children's usage, or example: "Parents know exactly with whom their children communicate on Facebook $(\alpha=.83) ; 10$ items appeared to represent parents attitudes toward Facebook, for example: "Parents are usually against Facebook usage" $(\alpha=.72) ; 5$ items appeared to represent parents' level of familiarity with Facebook, for example: "Parents are familiar with Facebook and understand the activities of their children on it" $(\alpha=.69) ; 5$ items appeared to represent co-using Facebook with the children, for example: "Parents communicate with their children on Facebook" $(\alpha=.74) ; 5$ items appeared to represent their feelings of need for guidance on how to monitor their children's usage, for example: "Parents should turn to appropriate authorities to ask for help in guiding their children to use Facebook responsibly" $(\alpha=.71)$. Two items were erased because of low loadings. These five factors explained $49.03 \%$ of the variance (Table 1 ).

Table 1. Explanatory Factor Analysis of the Research Questionnaire Items

\begin{tabular}{|c|c|c|c|c|c|}
\hline & $\begin{array}{l}\text { Monitoring } \\
\qquad \begin{array}{l}\alpha=.83) \\
N=12\end{array}\end{array}$ & $\begin{array}{c}\text { Co-using } \\
(\alpha=.74) \\
N=5\end{array}$ & $\begin{array}{c}\text { Attitudes } \\
\left(\begin{array}{c}\alpha=.72) \\
\mathrm{N}=10\end{array}\right.\end{array}$ & $\begin{array}{c}\text { Guidance } \\
(\alpha=.71) \\
\quad N=5\end{array}$ & $\begin{array}{l}\text { Familiarity } \\
(\alpha=.69) \\
\quad N=5\end{array}$ \\
\hline $\begin{array}{r}\text { Parents make sure to know the } \\
\text { contents that their children are } \\
\text { expose to on Facebook }\end{array}$ & .662 & .198 & -.258 & .193 & .000 \\
\hline $\begin{array}{r}\text { Parents know exactly what their } \\
\text { children do on Facebook }\end{array}$ & .587 & .413 & .039 & .070 & .174 \\
\hline $\begin{array}{l}\text { parents know how much time their } \\
\text { children spend on Facebook }\end{array}$ & .610 & .263 & -.047 & .163 & -.031 \\
\hline $\begin{array}{r}\text { Most parents know the minimal } \\
\text { age for opening a Facebook } \\
\text { account, and they prevent their } \\
\text { children from registering until then }\end{array}$ & .653 & .096 & -.030 & .009 & .110 \\
\hline $\begin{array}{r}\text { Children open Facebook accounts } \\
\text { after they get their parents' } \\
\text { permission to do so }\end{array}$ & .669 & .005 & -.066 & -.086 & -.034 \\
\hline
\end{tabular}


Parents know how much time their

Parents know exactly with whom

Parents are used to limiting their

Facebook only if the children reveal their account password Parents know if their children hurt

Children share their Facebook

experience with their parents

Parents and children enjoy communicating with each other on

Parents communicate with their

Facebook promotes children in

Facebook helps children make new

Facebook is dangerous for children

Parents want their children to

reduce their Facebook activity children's development

Many parents oppose their

children's use ofFacebook

In general, parents are against

Facebook

If parents dared, they would 
Facebook harms children's abilities to develop interests

Facebook helps children make new friends

Parents use to get guidance on

Facebook from professionals Many parents feel they don't know enough about Facebook and they want to have an address for guidance

Parents want educational authorities to help and guide the children about Facebook

If school would organize an evening to explain Facebook, many parents would attend to increase their ability to guide their children about Facebook

Parents must turn to appropriate authorities, asking for help on how to guide their children toward responsible Facebook use

Most parents are not familiar with Facebook and tend not to use it Parents understand and know what Facebook is Parents use Facebook by themselves and are clear of their different uses on it

Parents are familiar with Facebook and understand their children's activities on it

Most parents are not familiar with Facebook and don't understand the

\begin{tabular}{|c|c|c|c|c|}
\hline .121 & .010 & .692 & .100 & -.049 \\
\hline .015 & .218 & .557 & .227 & -.028 \\
\hline .040 & .359 & -.225 & 434 & -.208 \\
\hline-.030 & -.038 & -.135 & .758 & .016 \\
\hline .343 & .165 & .080 & .598 & -.158 \\
\hline -.007 & -.089 & -.071 & .780 & .096 \\
\hline . 171 & .174 & .264 & .683 & -.185 \\
\hline 等. & -.170 & -.009 & .008 & .673 \\
\hline .211 & .401 & .022 & .023 & .478 \\
\hline .051 & .121 & .251 & .327 & .581 \\
\hline .461 & . 252 & -.138 & .152 & .510 \\
\hline 197. & .031 & .201 & -.007 & .629 \\
\hline
\end{tabular}
reason to get an account

\subsection{Sampling Procedure}

The researchers used the snow ball method to locate participants, and made an effort to keep equal numbers of men and women, Jews and Arabs and parents of young children (under 13 years old) and older (above 13 years old).

\subsection{Research Procedure}

Participation was voluntary and parents were assured that their anonymity would be preserved. The parents gave their consent to participate in the research and were told that they could leave the study at will. Printed questionnaires were given to 140 parents who attended parents' meetings at school, and who returned them at the same time (filling a questionnaire lasted about 30 minutes). 85 parents were asked to participate via email (their email addresses were delivered by some of the participants). Those who gave their consent received the questionnaire by email and 55 returned it within a few hours or days. In sum, 225 questionnaires (printed and mailed) were delivered and 195 (87\%) were returned.

\section{Results}

MANOVA was the tool used to examine the parents' general attitudes and behavior regarding Facebook, distinguishing between mothers and fathers (Hypotheses 1), Jews and Arabs (Hypotheses 2), and parents of children younger and older than 13 (Hypotheses 3). The independent variables were Parent's gender, Parent's ethnic origin and Children's age. The five variables - Monitoring, Co-using, Familiarity with Facebook, Attitudes toward Facebook and Need for guidance - were the dependent variables. In general, and based on a 1-4 
Likert scale, parents tend to express relatively low to medium levels of monitoring of children's Facebook usage $(M=2.14, S D=0.58)$, familiarity with Facebook $(M=2.38, S D=0.59)$, positive attitudes $(M=2.23, S D=$ $0.43)$ and co-using $(M=1.95, S D=0.62)$. Overall, they express a relatively higher need for guidance $(M=2.48$, $S D=0.62$ ).

\subsection{Gender Differences}

As we assumed in our first hypothesis, the MANOVA yielded a main effect for gender, $F_{(5,183)}=4.30, p<.01$. In order to assess the differences between mothers and fathers, an ANOVA test was performed. The results yielded significant difference between the groups on two of the five variables: Attitude toward Facebook [Univariate $F$ $\left.{ }_{(1,187)}=6.36, p<.05\right]$, and Need for guidance [Univariate $\left.F_{(1,187)}=14.06, p<.001\right]$ : Mothers showed more negative attitude toward Facebook $(M=2.17, S D=0.42)$ than fathers $(M=2.34, S D=0.42)$. Mothers also showed higher need of guidance $(M=2.62, S D=0.59)$ than fathers $(M=2.27, S D=0.60)$. No significant differences were found between genders on Monitoring [Univariate $F_{(1,187)}=3.19, p>.05$ ], on Co-using Facebook with children, [Univariate $F_{(1,187)}=0.97, p>.05$ ], and Familiarity with Facebook, [Univariate $F_{(1,187)}=$ $0.20, p>.05]$.

In addition, no significant interaction was found of ethnic group by gender for the five dependent variables, $F_{(5,187)}=0.34, p>.05$. Similarly, no interaction was found with age group $F_{(5,187)}=0.49, p>.05$ and with both variables - gender and ethnic group $F_{(5,187)}=0.42, p>.05$.

Differences were found only in two of the five dependent variables in this hypothesis. We therefore set out next to seek inter-correlations among the dependent variables in each gender separately, to see whether some correlations were found among fathers and mothers. As shown in Table 2, most of the significant correlations are similar among fathers and mothers, except for Co-using, which was significantly and positively correlated with Attitudes toward Facebook $\left(r_{p}=0.25, p<.05\right)$, only among fathers. In addition, Familiarity with Facebook was significantly and positively correlated with Need for guidance only among mothers $\left(r_{p}=0.18, p<.05\right)$.

Table 2. Inter-correlations between dependent variables for Each Gender

\begin{tabular}{llrrrr}
\hline Gender & Factor & Co-using & Attitude & Familiarity & Need for guidance \\
\hline Male & Monitoring & $.71^{* *}$ & .17 & $.47^{* *}$ & $.43^{* *}$ \\
$N=76$ & Co-using & & $.25^{*}$ & $.42^{* *}$ & $.32^{* *}$ \\
& Attitude & & & .16 & -.08 \\
& Familiarity & & & & -.03 \\
\hline Female & Monitoring & $.58^{* *}$ & .12 & $.47^{* *}$ & $.54^{* *}$ \\
$N=119$ & Co-using & & .13 & $.58^{* *}$ & $.45^{* *}$ \\
& Attitude & & & .07 & .05 \\
& Familiarity & & & & $.18^{*}$ \\
${ }^{*} p<.05$ & & & & & \\
$* * p<.01$ & & & & &
\end{tabular}

\subsection{Differences between Jews and Arabs}

As for our second hypothesis regarding differences in the five variables measured between Jews and Arabs, again as expected, the MANOVA yielded a main effect for ethnic groups, $F_{(5,183)}=5.25, p<.001$. The ANOVA test, conducted to assess the differences between Jews and Arabs, revealed significant difference in two of the five variables measured: Monitoring children's Facebook usage [Univariate $F_{(1,187)}=7.67, p<.01$ ] and Need of guidance [Univariate $\left.F_{(1,187)}=15.10, p<.001\right]$. In those variables Arabs showed as expected, higher levels of Monitoring children's Facebook usage $(M=2.31, S D=0.57)$ than Jews $(M=2.05, S D=0.57)$, as well as Need of guidance $(M=2.69, S D=0.56$ and $M=2.37, S D=0.62$, respectively). No significant differences were found for Co-using Facebook with children [Univariate $F_{(1,187)}=2.83, p>.05$ ], Familiarity with Facebook [Univariate $F_{(1,187)}=2.24, p>.05$ ], and Attitude toward Facebook [Univariate $\left.F_{(1,187)}=0.22, p>.05\right]$. Also, no significant interaction was found of ethnic group by any independent variable for the five variables.

Inter-correlations among the dependent variables in each ethnic group separately (Table 3), yielded that most of the significant correlations are similar among Jews and Arabs. The exception was the significant and positive 
correlation, found only among Jews, between Co-using and Attitudes ( $r p=0.19, p<.05)$, and between Familiarity and Attitudes $\left(r_{p}=0.19, p<.05\right)$.

Table 3. Inter-correlations between Variables for Each Ethnic Group

\begin{tabular}{|c|c|c|c|c|c|}
\hline $\begin{array}{l}\text { Ethnic } \\
\text { group }\end{array}$ & Factor & Co-using & Attitude & Familiarity & Guidance \\
\hline Jews & Monitoring & $.61^{* *}$ & .07 & $.50^{* * *}$ & $.46^{* *}$ \\
\hline \multirow{3}{*}{$N=127$} & Co-sharing & & $.19^{*}$ & $.53^{* *}$ & $.41^{* *}$ \\
\hline & Attitude & & & $.19^{*}$ & -.14 \\
\hline & Familiarity & & & & .13 \\
\hline Arabs & Monitoring & $.63^{* *}$ & .13 & $.51^{* *}$ & $.54^{* *}$ \\
\hline \multirow[t]{3}{*}{$N=68$} & Co-sharing & & .08 & $.59^{* *}$ & $.36^{* *}$ \\
\hline & Attitude & & & -.01 & .05 \\
\hline & Familiarity & & & & .10 \\
\hline
\end{tabular}

\subsection{Differences between Parents of Children under and over 13}

Regarding our third hypothesis on differences between parents of children under and over 13, again the MANOVA yielded a main effect $F_{(5,183)}=2.18, p<.05$. The ANOVA that was performed in order to assess the differences between parents of children in those ages yielded significant difference between the groups in only one of the five variables measured - Co-using [Univariate $F_{(1,187)}=3.87, p<.05$ ]. Parents of children under 13 showed lower levels of Co-using $(M=1.88, S D=0.54)$ than parents of children over $13(M=2.11, S D=0.73)$. No significant difference was found between parents of children under and over13, regarding the other four variables measured: Monitoring [Univariate $F_{(1,187)}=1.30, p>.05$ ], Attitude [Univariate $F_{(1,187)}=0.34, p>.05$ ], Need of guidance [Univariate $F_{(1,187)}=1.35, p>.05$ ], and Familiarity [Univariate $F_{(1,187)}=2.69, p>.05$ ].

Also, no significant interaction was found for ethnic group with any independent variable for the five variables.

Inter correlations among the dependent variables in each children's age group separately (Table 4), revealed that most of the significant correlations are similar in both age groups, except for the significant and positive correlations found only among parents of children over 13, between Co-using and Attitudes $\left(r_{p}=0.22, p<.05\right)$, and between Familiarity and Need for guidance $\left(r_{p}=0.32, p<.01\right)$.

Table 4. Inter-correlations between Variables for Each Children's Aage Group

\begin{tabular}{llrrrr}
\hline Age & Factor & Co-sharing & Attitude & Familiarity & Guidance \\
\cline { 2 - 6 } Under 13 & Monitoring & $.50^{* *}$ & .11 & $.39^{* *}$ & $.45^{* *}$ \\
$N=132$ & Co-sharing & & .08 & $.47^{* *}$ & $.33^{* *}$ \\
& Attitude & & & .13 & -.04 \\
& Familiarity & & & & -.03 \\
\hline Over 13 & Monitoring & $.80^{* *}$ & .07 & $.57^{* *}$ & $.67^{* *}$ \\
$N=63$ & Co-sharing & & $.22^{*}$ & $.61^{* *}$ & $.59^{* *}$ \\
& Attitude & & & .07 & -.10 \\
& Familiarity & & & $.32^{* *}$ \\
\hline
\end{tabular}

$* p<.05$

$* * p<.01$ 


\subsection{Demographic Background and Level of Monitoring}

In regards to the association between parents' demographic backgrounds and their level of monitoring and attitudes toward Facebook, a linear multiple stepwise regression was conducted for each one of the five dependent variables (Monitoring, Co-using, Familiarity, Attitudes, Need for guidance). The participant's demographic background (Ethnic group, parents' gender, Parents having a Facebook account, Parents' educational level, Number of computers at home, Location of the computer at home and Knowing the child's Facebook password) were entered as predicted (explanatory) variables; The order of the variables entered in the regression model was determined by their relationship with the dependent variables. The regression analysis reveal that parent's gender was a significant predictor of Monitoring with adjusted $R^{2}=.17,\left[F_{(3,180)}=6.36, p<0.001\right]$, Attitudes with adjusted $R^{2}=.16,\left[F_{(4,131)}=6.21, p<.001\right]$, and Need of guidance with adjusted $R^{2}=.24,\left[F_{(3,132)}=14.87, p<.001\right]$. According to the $\beta$ coefficients we get to learn that mothers predict higher levels of Monitoring than fathers, higher Need for guidance, and more negative Attitudes ( $\beta=.155,-.197$ and -.301 respectively).

In regard to the variable Ethnic origin, the regression analyses reveal that this variable predicts Monitoring with adjusted $R^{2}=.17,\left[F_{(3,180)}=6.36, p<.001\right]$, Familiarity with adjusted $R^{2}=.15,\left[F_{(3,132)}=7.79, p<.001\right]$, and Need for guidance with adjusted $R^{2}=.24,\left[F_{(3,132)}=14.87, p<.001\right]$. According to the $\beta$ coefficient, Jews were found with higher levels of Familiarity than Arabs, and Arabs expressed higher levels of Monitoring and higher Need for guidance than Jews ( $\beta=.185,-.231$ and.387 respectively)

The regression analyses also reveal that the variable child's age is a predictor of parents' Attitudes, with adjusted $R^{2}=.16,\left[F_{(4,131)}=6.21, p<.001\right]$ : According to the $\beta$ coefficient, parents of children over 13, predict more positive Attitudes than their counterparts with children under 13 ( $\beta=.037$ ).

The independent variable Knowing the child's password was also found to be a significant predictor of four of the five independent variables. Parent having a Facebook account, was also found as a significant predictor of thee of the five independent variables. The variable Number of computers at home was also found as a significant predictor of one of the five independent variables (Attitudes toward Facebook).

\subsection{Summary of the Results}

In sum, our findings show that, in general, parents tend to express relatively moderate to low supportive attitudes and moderate to low levels of awareness and involvement in children's use of Facebook.

Our first hypothesis was confirmed regarding two of the variables: as we expected, fathers expressed more positive Attitudes toward Facebook, and mothers showed greater Need for guidance. Unlike our expectation, no significant differences were found between fathers and mothers regarding levels of Monitoring, Co-using, and Familiarity with Facebook. In addition, among fathers, a positive correlation was found between Attitudes and Co-using; among mothers, a positive correlation was found between Familiarity and Need for guidance. Parents' gender was found to be a significant predictor of Monitoring, Attitudes, and Need for guidance.

Our second hypothesis was confirmed regarding two of the variables as well: As we expected, Arab parents were found higher than Jews in Monitoring and in Need for guidance. Unlike our expectation, no significant differences were found between Jews and Arabs regarding Attitudes, Familiarity, and Co-using. Among Jews only, we found a positive correlation between Co-using and Attitudes, and between Familiarity and Attitudes. Ethnic origin was found as a predictor of parents' Monitoring, Familiarity, and Need for guidance.

Our third hypothesis was not confirmed. In four of the five variables measured, parents of children over 13 were found to be similar to parents of children under 13: Monitoring, Need for guidance, Familiarity, and Attitudes. In contrast to our expectation, parents of the older children were found higher in Co-using than parents of the younger children. Positive correlation was found only among the parents of children over 13 between Attitudes and Co-using, and between Familiarity and Need for guidance. The child's age was found to be a significant predictor of parents' Attitudes toward Facebook.

\section{Discussion}

This study was intended to expand our knowledge of parents' behavior and attitudes in relation to children's use of Facebook . Specifically, attitudes and behavior were examined from the perspective of parents' gender and ethnic origion, and according to the age of their children.The study focused on five aspects: (1) Parents' monitoring of children's Facebook use, (2) Parents' attitudes toward Facebook, (3) Child-parent co-using, (4) Parents' familiarity with Facebook, and (5) Parents' feelings of need for guidance on how to direct their children to use Facebook appropriately and safely. In general, our results show that parents involvement with all five aspects examined was moderate to low. 
A possible explanation for the gender difference we found, regarding the mothers' greater need for guidance, might be associated with former findings regarding women's higher tendency than men's to seek professional counseling and guidance (Hsiaowen, 2007; Turkum, 2005). However, because these are also the mothers who express less positive attitudes toward Facebook (in contrast to fathers), we found, as we expected, that mothers perceive Facebook usage as possibly justifying guidance. This can also be associated with the fact that up to today "mothers spend more time in caregiving, joint activities, and conversation with their adolescents compared to fathers" (Liau et al., 2008, p. 220), and as a result know more about their children's daily lives (Bumpus, Crouter, \& McHale, 2001; Waizenhofer et al. 2004). Awareness of risks and potential negative outcomes that might accompany Facebook usage - might explain their reservations from Facebook, and lead them to feel stronger need for guidance on how to protect their children and how to direct them to a safe Facebook usage. When this finding is combined with the positive correlation between Familiarity with Facebook and Need for guidance among mothers only, it could be indicative of mothers' strong feeling of involvement: The more they understand what Facebook is all about, and although this understanding was found in a positive correlation with positive attitudes, the stronger is their feelings of need for guidance. This relationship between Familiarity and Need for guidance is in line with Livingstone and Bober (2005) who state that a significant number of parents express a need for better information and advice regarding their children's internet usage. However, mothers' higher need for guidance and higher reservations about Facebook, could lead us to expect, as hypothesized, that mothers will show higher levels of Co-using and Monitoring than fathers. However, while we expected these differences and did not find them, a regression analysis yielded that mothers predict higher levels of monitoring than fathers.

When comparing Jews and Arabs, we see that as expected, Arabs are higher in Monitoring than are Jews, and like mothers, they also express higher Need for guidance. This may be characteristic of a society which gives priority to tradition, family values, and authority, and finds it important to keep children's obedience (Sagy et al., 2001). The "wave" of internet and Facebook use has mostly swept the young generation in Arab society. It therefore stands to reason that Arab parents, who are not widespread internet users (Kan-Naim, 2011), will feel greater Needs for guidance. In other words, we can expect the digital gap to be stronger among Arab parents, who perceive the internet as less available, than among Jewish parents. Our findings also reveal that among Jews only, there is a positive correlation between Familiarity with Facebook and Attitudes. This correlation was not found among the Arab parents in our sample, possibly due to their lower internet use. However, these findings may also indicate a transition that the Israeli Arab society is going through: Together with the differences in Monitoring and Need of guidance, Arab parents' reports are not significantly different from Jewish parents in their Attitudes Familiarity and Co-using. In the current study these similarities are relevant to a smaller group of the participants since the Arab participants in our sample - parents and children alike - are less active on the internet than their Jewish counterpart. However, while considering those who actually have a Facebook account, it is possible that these similarities are also an indication of a society in transition, which holds traditional values and at the same time is influenced by modern Western values.

The entire sample yields a relatively low level of parental Monitoring. These findings are in accordance with Cho and Cheon (2005) and Liau et al. (2008) who report on low levels of parents' internet usage supervision. Low supervision is understood in light of our finding that the vast majority of the parents in our study do not know their children's Facebook password, and that most children use the computer at home in privacy.

It is not surprising that about $75 \%$ of the parents in our sample claim that they do not know whether their child harasses others or has been harassed while using Facebook. This finding support former research (Cho \& Cheon, 2005; Liau et al., 2008; Livingston \& Bober, 2004), and we find these finding especially troubling considering the high rate of children under the age of 13 ( $82 \%$ in our sample), who are registered to Facebook - against regulations.

Parents of younger and of older children reported similar levels of Monitoring. Again our analysis did not match our expectation that parents of younger children will show higher levels of monitoring. The difference between parents of younger and older children was in Co-using. Here, contrary to our expectations, parents of older children expressed greater tendency toward mutual activity on Facebook than did parents of younger children.

The overall picture that emerges from this study, leads us to wonder why parents, who are aware of the risks, do not monitor their children's activity more closely, especially younger children's activities. Another interesting question is why do parents tend to co-use Facebook more frequently with their relatively older children?

Three possible answers to these questions are: (a) While low monitoring level can be perceived as permissive behavior, it can be also be a result of the digital gap (Boniel-Nissim, 2010; Prensky, 2001), and the parents' lack of skills and knowledge on how exactly to supervise their children. (b) Lack of relevant knowledge, and low 
awareness of potential risks, may lead parents to assume that their younger children do not put themselves in danger while using Facebook, as they seem to be involved in innocuous activities such as playing games and chatting with their friends. Such activity does not interest parents very much nor does it concern them greatly, hence the low level of involvement. (c) Because registration to Facebook is limited to those over 13 years of age, younger children provide a false date of birth. It is possible that parents are not comfortable with the situation in which they actually let their children register this way, and express this discomfort by being indifferent to their children's activity, or even ignoring it. The end result is a low level of Monitoring and of Co-using. However, when the child is older, this is no longer the case, and it is possible, that parents prefer to co-use Facebook with their teenager children to enable them to stay connected with their adolescent child, at a stage usually parental involvement decreases. This explanation seems reasonable, together with our finding that show positive correlation among the more involved parents, between Attitudes and Co-using. Overall, older adolescents spend less time with their parents and more time with their peers (Mesch, 2003; Yeung, Sandberg, Davis-Kean, \& Hofferth, 2001), so that Co-using adds a new form of communication to the parent-adolescent relationship, a form less needed between parents and their younger children. It is also possible that co-using with a teenager is more interesting and challenging to the parents, who can improve their own internet skills simply by learning from their child.

\subsection{Conclusions}

Our findings highlight the emergent need for creating a governmental plan, perhaps through cooperation between the ministries of education and justice, for an intervention program for parents. Such a program should define parents' responsibility toward children's internet use, and improve their ability to direct their children's internet activity so it will be safe and responsible. The education system in Israel is already aware of the need to guide pupils in these directions. Programs developed and implemented for this purpose include explanations on internet risks and on a safe internet use in computer lessons throughout the year, and .focused days dedicated to this issue.

However, our findings suggest that these actions are not yet sufficient to ensure safe and responsible children's internet usage. The data described in this study show that parents let their children register before the allowed age, give full internet use privacy to very young children while assuming there are safe, and lack internet skills that prevent them appropriate directing and monitoring. These lead us to conclude much more explanation is required. Any intervention program designed must be culturally sensitive, and address different levels of computer exposure and computer literacy among the various subgroups in society.

\subsection{Research Limitations}

To the best of our knowledge, this research is the first to combine the different aspects chosen here - Monitoring, Guidance, Attitudes, Familiarity and Co-using, while focusing on parents' point of view in relation to a significant internet activity for children - their Facebook usage. Nonetheless, several main limitations are worth mentioned: (a) The study is based on a relatively small convenience sample of parents; (b) It is based exclusively on the parents' self-reports; (c) Although a major effort had been made to include equal proportions of mothers and fathers, Jews and Arabs and parents of younger and older children, the sample is not sufficiently balanced; (d) The research design does not allow us to distinguish clearly between the possible influence of gender, ethnic origin, and child's age and parents' internet behavior; (e) The issue of parents' attitudes and norms about Facebook usage of their children may be quite different depending on the child's age and the range included in this study is rather wide. More research is needed, using larger and more representative samples, and additional instruments, such as questionnaires administered to parents and interviews with both adolescents and their parents.

\section{References}

Baker, L. R., \& Oswald, D. L. (2010). Shyness and online social networking services. Journal of Social and Personal Relationships, 27 (7), 873-889. http://dx.doi.org/10.1177/0265407510375261

Bjornstad, T. L., \& Ellingsen, T. (2004). Onliners: A report about youth and the Internet. SAFT. Retrieved from http://www.saftonline.org/On-Liners

Boniel-Nissim, M. (2010). I like it or I don't: The social network Facebook (and its language) challenge the education system. Bimat Diun (Discussion Platform), 44, 46-48 (in Hebrew).

Bumpus, M. F., Crouter, A. C., \& McHale, S. M. (2001). Parental autonomy granting during adolescence: Exploring gender differences in context. Developmental Psychology, 37, 163-173. http://dx.doi.org/10.1037//0012-1649.37.2.163

Ceyhan, A. A. (2011). University students' problematic Internet use and communication skills according to the internet use purposes. Theory and Practice, 11(1), 69-77. 
Cho, C-H., \& Cheon, H. J. (2005). Children's Exposure to negative internet content: Effects of family context. Journal of Broadcasting and Electronic Media, 49 (4), 488-509. http://dx.doi.org/10.1207/s15506878jobem4904_8

Cole, J. I., Suman, P., Schram, D., Van Bel, B., Lun, P., Maguirre, K., Hanson, R., S., \& Aquino, J. S. (2000). Surveying the digital future. Los Angeles, CA: UCLA Center for Communication Policy. Los Angeles. Retrieved from www.ccp.ucla.edu

Dwairy, M., \& Achoui, M. (2006). Introduction to three cross-regional research studies on parenting styles. Journal of Cross-Cultural Psychology, 37, 221-229. http://dx.doi.org/10.1177/0022022106286921

Finkelhor, D., Mitchell, K. J., \& Wolak, J. (2000). Online victimization: A report on the nation's youth. National Center for Missing and Exploited Children. Retrieved from http://www.ncmec.com/

Fleming, M. J., \& Rickwood, D. J. (2001). Effects of violent versus nonviolent video games on Children's arousal, aggressive mood, and positive mood. Journal of Applied Social Psychology, 31, 2047-2071. http://dx.doi.org/10.1111/j.1559-1816.2001.tb00163.x

Garcia-Mainar, I., Molina, J. A., \& Montuenga, V. M. (2011). Gender differences in childcare: Time allocation in five European Countries. Feminist Economics, 17 (1), 119-150. http://dx.doi.org/10.1080/13545701.2010.542004

Gray, D., \& Christiansen, L. (2010). A call to action: The privacy dangers adolescents face through use of Facebook.com. Journal of Information Privacy \& Security, 6(2), 17-32.

Hsiaowen, C. (2007). Psychological distress and help-seeking among Taiwanese college students: Role of gender and student status. British Journal of Guidance \& Counselling, 35(3), 347-355. http://dx.doi.org/10.1080/03069880701418789

Inside Facebook.com. (2010). $\quad$ Retrieved from http://www.insidefacebook.com/2010/07/06/facebooks-june-2010-us-traffic-by-age-and-sex-users-aged-1844-take-a-break-2/

Israel Census Bureau. (2010). Statistical abstract of Israel. Retrieved from http://www.cbs.gov.il/shnaton61/st02_19.pdf (in Hebrew).

Johansson, A., \& Gotestam, G. (2004). Internet addiction: Characteristics of a questionnaire and prevalence in Norwegian youth (12-18 years). Scandinavian Journal of Psychology, 45, 223-229. http://dx.doi.org/10.1111/j.1467-9450.2004.00398.x

Kan-Naim. (2011). Retrived from http://www.kan-naim.co.il/artical.asp?id=17000\&cid=88

Kiesler, S., Zdaniuk B., Lundmark, V., \& Kraut, R. (2000). Troubles with the Internet: The Dynamics of Help at Home. Human Computer Interaction, 15, 322-351. http://dx.doi.org/10.1207/S15327051HCI1504_2

Kim, J. U. (2007). A Reality therapy group counseling program as an internet addiction recovery method for college students in Korea. International Journal of Reality Therapy, 26 (2-3), 3-9.

Lăzărescu, M. P. (2010). Considerations on the impact of television and internet over the children's and teenagers' behavior. Petroleum-Gas University of Ploiesti Bulletin, Educational Sciences Series, 62 (1A), 96-101.

Lee, S. J., \& Chea, Y. G. (2007). Children's Internet use in a family context: Influence on family relationships and parental mediation. Cyberpsychology and Behavior, 10 (5), 640-644. http://dx.doi.org/10.1089/cpb.2007.9975

Lenhart, A. (2005). Protecting teens online. Washington, DC: Pew Internet and American Life Project. Retrieved from http://www.pewinternet.org/PPF/r/152/report_display.asp

Lenhart, A., \& Madden, M. (2007). Teens, privacy and online social networks: How teens manage their online identities and personal information in the age of MySpace. Washington, DC: Pew Internet and American Life Project. Retrieved from http://www.pewinternet.org/PPF/r/211/report_display.asp.

Lenhart, A., Purcell, K., Smith, A., \& Zickuhr, K. (2010). Social media and mobile Internet use among teens and young adults. Retrieved from http://74.125.155.132/scholar?q=cache:E6_UjIWWXWQJ:scholar.google.com/+teens++Facebookandhl=iw andas_sdt $=0,5$

Liau, A. K., Khoo, A., \& Ang, P. H. (2005). Factors influencing adolescent engagement in risky internet behavior. 
Cyberpsychology and Behavior, 8, 513-520. http://dx.doi.org/10.1089/cpb.2005.8.513

Liau, A. K., Khoo, A., \& Ang, P. H. (2008). Parental awareness and monitoring of adolescent internet use. Current Psychology, 27, 217-233. http://dx.doi.org/10.1007/s12144-008-9038-6

Lim, C. P., Khoo, A., \& Williams, M. D. (2003). A comparison of Singapore parents and children's use of the Internet and perceptions of its dangers. Journal of APEC Studies, 5(1), 85-103.

Livingstone, S. (2003). Children's use of the internet: Reflections on the emerging research agenda. New media and society, 5(2), 147-166. http://dx.doi.org/10.1177/1461444803005002001

Livingstone, S., \& Bober, M. (2004). UK Children Go Online: Surveying the experiences of young people and their parents. Retrieved from www.children-go-online.net

Livingstone, S., \& Bober, M. (2005). UK Children Go Online: Final report of key project findings. Retrieved from http://www.lse.ac.uk/collections/children-go-online/UKCGOfinalReport.pdf

Mesch, G. S. (2003). The family and the Internet: The Israeli case. Social Science Quarterly 84(4), 1038-1050. http://dx.doi.org/10.1046/j.0038-4941.2003.08404016.x

Mitchell, K. J., Finkelhor, D., \& Wolak, J. (2001). Risk factors for and impact of online sexual solicitation of youth. The Journal of the Americam Medical Association, 285, 3011-3014. http://dx.doi.org/10.1001/jama.285.23.3011

National School Boards Foundation (2008). Research and guidelines for children's use of the Internet. Retrieved from http://grunwald.com/pdfs/Grunwald_NSBA_Study_Safe\%20and\%20Smart.pdf

New York Times (27.5.2011). Facebook. Retrieved from http://topics.nytimes.com/top/news/business/companies/Facebook_inc/index.html

News1, (2012). Facebook has over than a billion users. Retrieved from http://www.news1.co.il/Archive/001-D-310922-00.html (in Hebrew).

O'Keeffe, G., \& Clarke-Pearson, K. (2011). The impact of social media on children, adolescents, and families. Pediatrics, 127(4), 800 -804. http://dx.doi.org/10.1542/peds.2011-0054

Prensky, M. (2001). Digital natives, digital immigrants. On the Horizon (MCB University Press), 9(5), 1-6. Retrieved from http://www.marcprensky.com/writing/prensky\%20-\%20digital\%20natives, \%20digital\%20immigrants\%20\%20part1.pdf

Sagy, S., Orr, E., Bar-on, D., \& Awwad, E. (2001). Individualism and collectivism in two conflicted societies: Comparing Israeli-Jewish and Palestinian-Arab high school students. Youth and Society, 33, 3-30. http://dx.doi.org/10.1177/0044118X01033001001

Sivan, E. (1995). The enclaved culture. Chicago: Chicago University Press.

Sook-jung, L., \& Young-gil, C. (2007). Children's Internet use in a family context: Influence on family relationships and parental mediation. Cyber Psychology and Behavior, 10 (5), 640-644. http://dx.doi.org/10.1089/cpb.2007.9975

Steyer, J. P., \& Clinton, C. (2003). The other parent: The inside story of the media's effect on our children. New York: Atria Books.

Sun, P., Unger, J. B., Palmer, P. H., Gallaher, P., Chou, C. P., Baezconde-Garbanati, L., et al. (2005). Internet accessibility and usage among urban adolescents in Southern California: Implications for web-based health research. Cyberpsychology and Behavior, 8, 441-453. http://dx.doi.org/10.1089/cpb.2005.8.441

Turkum, A. S. (2005). Who seeks help? Examining the differences in attitude of Turkish university students toward seeking psychological help by gender, gender roles, and help-seeking experiences. Journal of Men's Studies, 13(3), 389-401. http://dx.doi.org/10.3149/jms.1303.389

Vax, N. (2011). Pupils in the Internet age. Science and Technology on Line Retrieved from http://www.matar.ac.il/research/99.11.asp (in Hebrew)

Waizenhofer, R. N., Buchanan, C. M., \& Jackson-Newsom, J. (2004). Mothers' and fathers' knowledge of adolescents' daily activities: Its sources and its links with adolescent adjustment. Journal of Family Psychology, 18, 348-360. http://dx.doi.org/10.1037/0893-3200.18.2.348

Wang, R., Bianchi, S. M., \& Raley, S. B. (2005). Teenagers' internet use and family rules: A research note. 
Journal of Marriage and Family, 67, 1249-1258. http://dx.doi.org/10.1111/j.1741-3737.2005.00214.x

Wartella, E., Lee, J. H., \& Caplovitz, A. G. (2002). Children and interactive media: An updated research compendium. Markle Foundation. Retrieved from http://www.digital-kids.net/modules.php?op=modloadandname=Downloadsandfile=indexandreq=viewdow nloadandcid $=2$

Yeung, W. J., Sandberg, J. F., Davis-Kean, P. E., \& Hofferth, S. L. (2001). Children's time with fathers in intact families. Journal of Marriage and Family, 63, 136-154. http://dx.doi.org/10.1111/j.1741-3737.2001.00136.x

$(\mathrm{cc}) \mathrm{Br}$

This work is licensed under a Creative Commons Attribution 3.0 License. 